\title{
SECTION OF PATHOLOGY.
}

\section{TYPICAL FRACTURES.}

\author{
By E. H. BENNETT, M.D., M.CH., F.R.C.S.; \\ Professor of Surgery in the University of Dublin.
}

[Read in the Section of Pathology, November 1, 1889.]

THE study of typical fractures may help to advance this branch of surgery. I think that much has yet to be learned by us all before we can make our diagnosis and treatment of fractures creditable to surgery. How discreditable to us are the vast majority of the specimens which fill our museums! If any doubt this, I would ask the sceptic to take his pick and choice from our museum shelves, and hunt up, as we can in our catalogues, and note the names of those who have treated the lesions during life. Many a pupil will blush to see the work of his master, and of this $I$ am certain, however he may pride himself on his own better and newer methods, if he test his work by the product of the macerating tub, he will find himself in no better position than his predecessors. To improve this state of things $I$ think we must improve our mode of study of this branch of pathology. If by any means we can make the study of fractures easier, more exact, and more interesting than it is at present, some of these opprobria of surgery with which our museums abound may be removed; or those that cannot be removed may more clearly be condoned. The help that I would offer is the direction of attention to the study of typical fractures.

In order that I may clear myself from a charge of self-conceit, or of talking mere platitudes in speaking to you about such a subject, which many of you may on the first view regard as an 
integral of the A B C of surgical pathology, let me quote from one of the most recent writers a passage which sets forth very clearly the position which the study of type holds in the modern surgical literature of fractures. Packard says, in his article in Ashurst's Encyclopædia-"If anyone studies a large number of fractures, placing them in series according to the portion of the skeleton involved, he may readily note a certain uniformity which prevails among the different members of each series. Variations do indeed exist, but they are traceable to differences, perhaps slight, in the character, direction, or exact mode of application of the fracturing force, or in the conditions of resistance, or perhaps in the shape of the bones themselves. The dominant lines of breakage are singularly constant, and although they have been pointed out in regard to certain special fractures, they have been overlooked in the general study of these injuries."

In this passage the term typical fracture, as I use it, is clearly defined, and the degree of development of its study is truly marked down to the year 1884 .

The character of the type is not rigid, but variable within certain narrow limits. "Facies non omnibus una nec diversa tamen qualem decet esse sororum." The essential basis of this study is a tripod-first, the shape and structure of the bone; second, the character of the fracturing force; and third, the character of the fracture.

When we have established by a sufficient pathological series the features of the type we can assert that the remaining legs of the tripod are present. The bones of the skeleton are fairly constant in form, in the distribution of their strength, and in their modes of degeneration.

They are liable to exceptional strain from external violence and from the action of the muscles attached to them. We find that under these exceptional strains which exceed the powers of their resistance "the brittle strength of bones" gives way and fractures result. The typical fracture being found, the constancy of the strength of the bone admitted, it follows that the force in any given instance must be a constant also. 


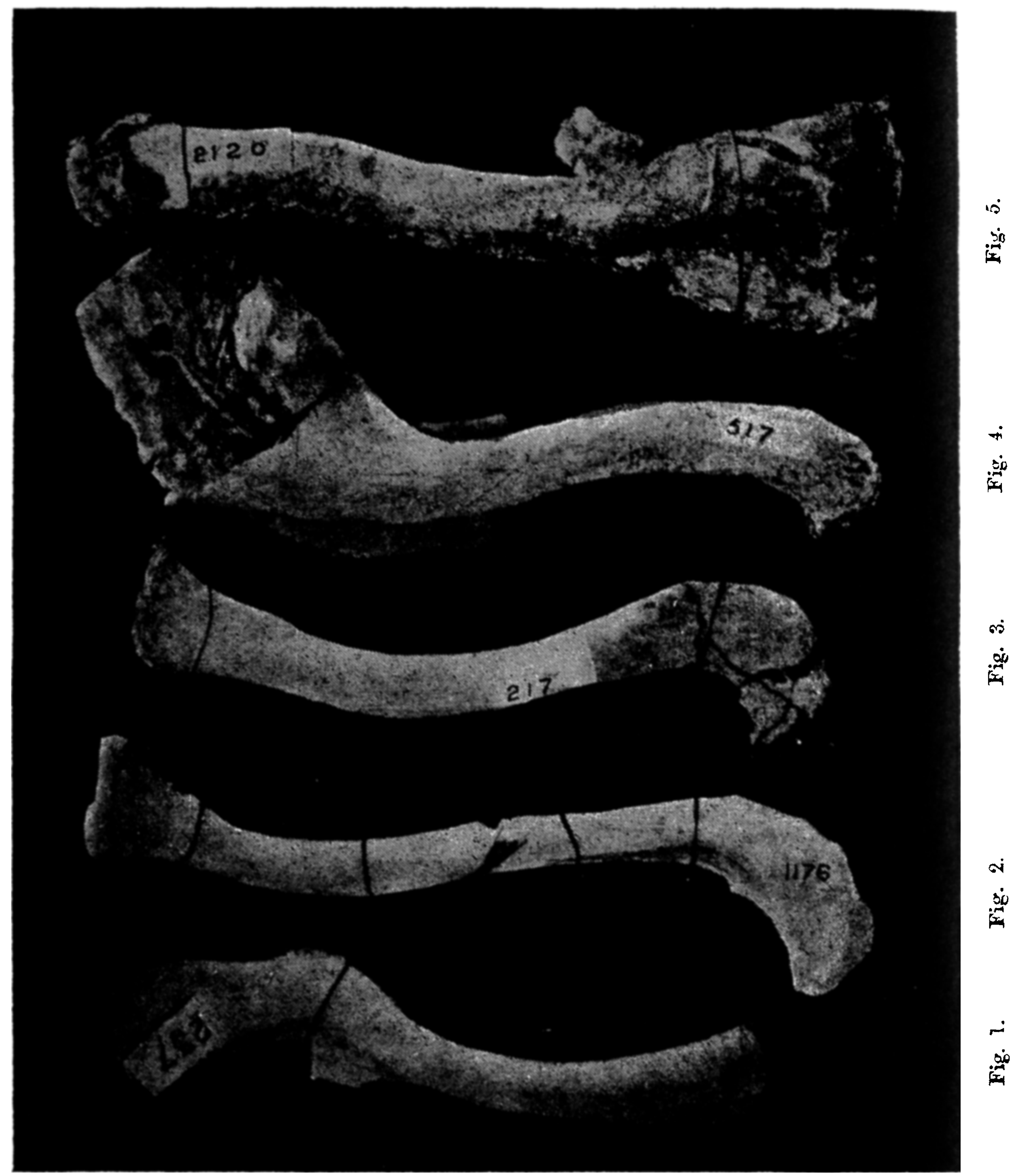

Fig. 1. United Ordinary Fracture. Fig. 2. Recent Ordinary Fracture. Fig. 3. Fracture External to Trapezoid Ligament, united by Fibrous Tissue. Fig. 4. United Fracture of Sternal End. Fig. 5. Experimental Fracture of the corresponding Bone. 
Put aside from our present consideration bullet injuries and great smashes of the limbs or trunk in machinery accidents and the like, and let us look to the more common fractures that daily fill our hospital wards and form the bulk of the united fractures of our museum collections. I make this limitation only to confine the scope of my address, not because the greater compound injuries of the skeleton are devoid of type. Their types are more difficult to trace, and neither the time at my disposal nor my own knowledge of them would justify my entering on so vast a search. All the world of surgical writers are agreed that fractures are caused by direct or indirect injuries, by muscular action, or by avulsion. Many have been content to carry the study of force thus far only, to state that a given fracture is the result of one or other of these kinds of force, and there leave the matter. I hold that this extent of knowledge, though in itself good, helps us but little in dealing with fractures at the bedside, which, after all, should be our great object.

Often we find that the determination of the kind of force which gives rise to most typical fracture has wholly escaped the notice of writers, or has been lost from view by the prejudice derived from absurd anatomical theory. For instance, the majority of writers attribute the ordinary fracture of the clavicle (Figs. 1 and 2) to indirect violence, which acts, according to their theory, in the axis of the bone. They say, "the part between the two curves is generally the weakest part of the bone, and hence more liable to fracture." Is there any ground for this statement as to the strength of the bone? None that I know of ; it is a mere assertion. I recollect well being taught that the clavicle broke in the ordinary manner because the pressure of a shock acting in the axis of the bone increased its curves, and the break must therefore be placed where the longitudinal axis cuts these curves. This is a theory quite different from that $I$ have just mentioned.

Here is another, from one of our standard authorities:-

"Most frequently the great convexity is broken, the bone bending here when pressed upon its extremity, the curve becoming increased, and at last giving way. This fracture may arise from 
direct violence, but usually is the result of falls on the hand or shoulder."

In this a fresh site is selected, and the force may be direct or indirect. These passages show that opinions are very various, and even contradictory, with regard to the most common fracture of the skeleton. They will with greater certainty be found so when less common lesions are under examination. Before leaving this particular example we may pause a moment to see the types of fracture in the several districts of the clavicle, and, it may be, appreciate the value of the mode of study $I$ advocate as an aid to diagnosis.

The ordinary fracture results from shocks very various in their kind, but reduced to order by the road by which they reach the clavicle.

When a man breaks his collar-bone in this fashion, it matters little whether he fall on his hand, his elbow, or the point of his shoulder. The force acts through the shoulder-joint and glenoid of the scapula, and the brunt of the battle is seated where the coraco-clavicular ligaments unite the bones. The clavicle gives way inside these always obliquely, and with only such variations as one can see must result from the great variety of strains possible.

In the typical fracture of the clavicle next in frequency (Fig. 3), that seated outside the coraco-clavicular ligaments, the bone breaks transversely; the force acts on the outer part of the spine of the scapula, either by the individual falling backwards, or by his being struck a heavy diffused blow on the same part.

Next in order of frequency is the fracture between the ligaments, caused by falls or blows, taking effect on the upper surface of the shoulder, or when the bone is enfeebled by atrophy by the mere weight of the upper limb; in this the clavicle breaks over the coracoid process as one breaks a stick on the knee.

The sternal end of the clavicle breaks with constant obliquity under a purely axial pressure (Figs. 4 and 5). A direct blow will break the bone anywhere where it strikes, and as is the rule in long bones, the lesion is transverse to the axis of the bone at the point struck. 
lig. 6.

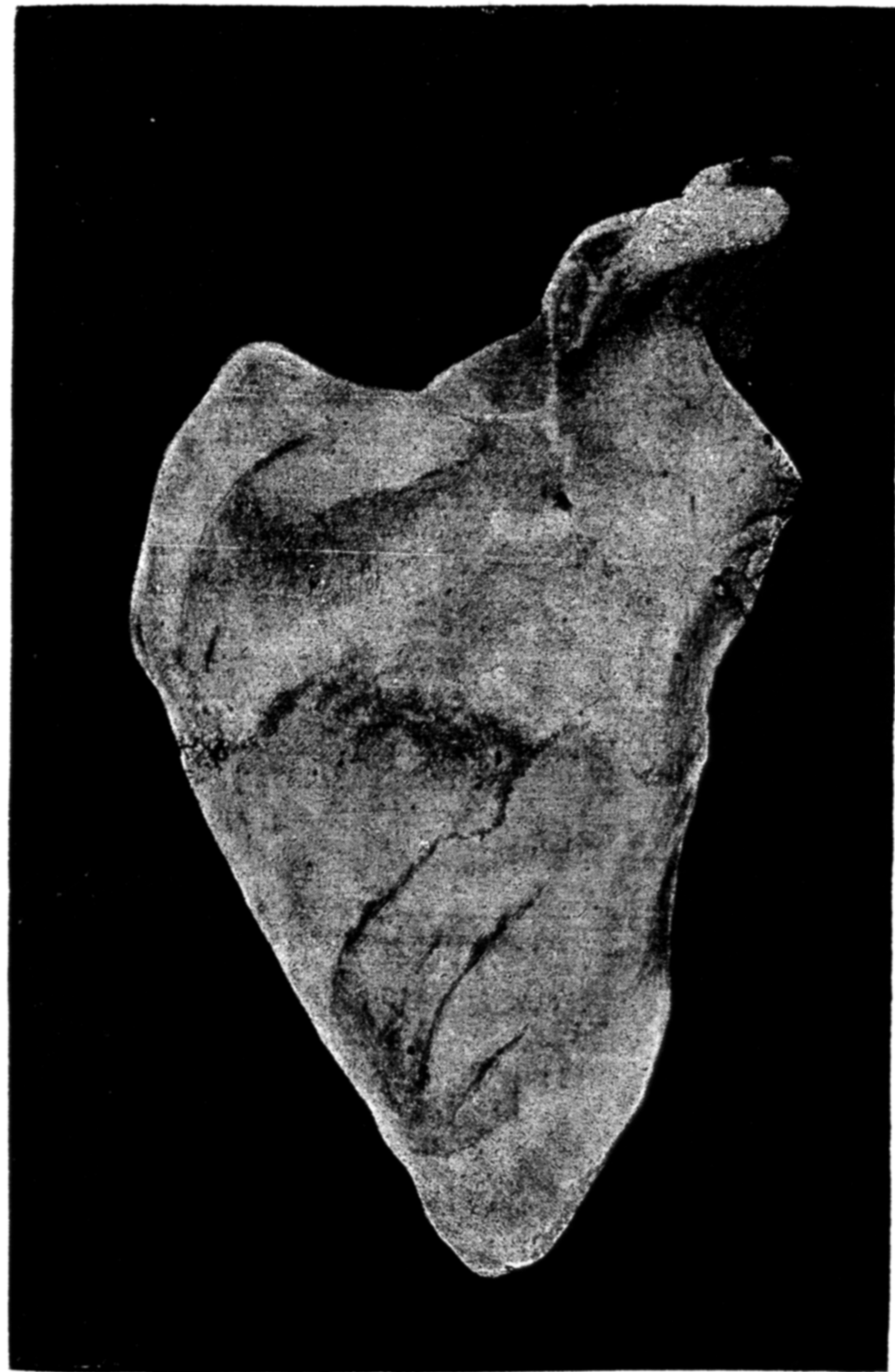

Horizontal Fracture (United) of the Scapula. 
Fig. 7 .

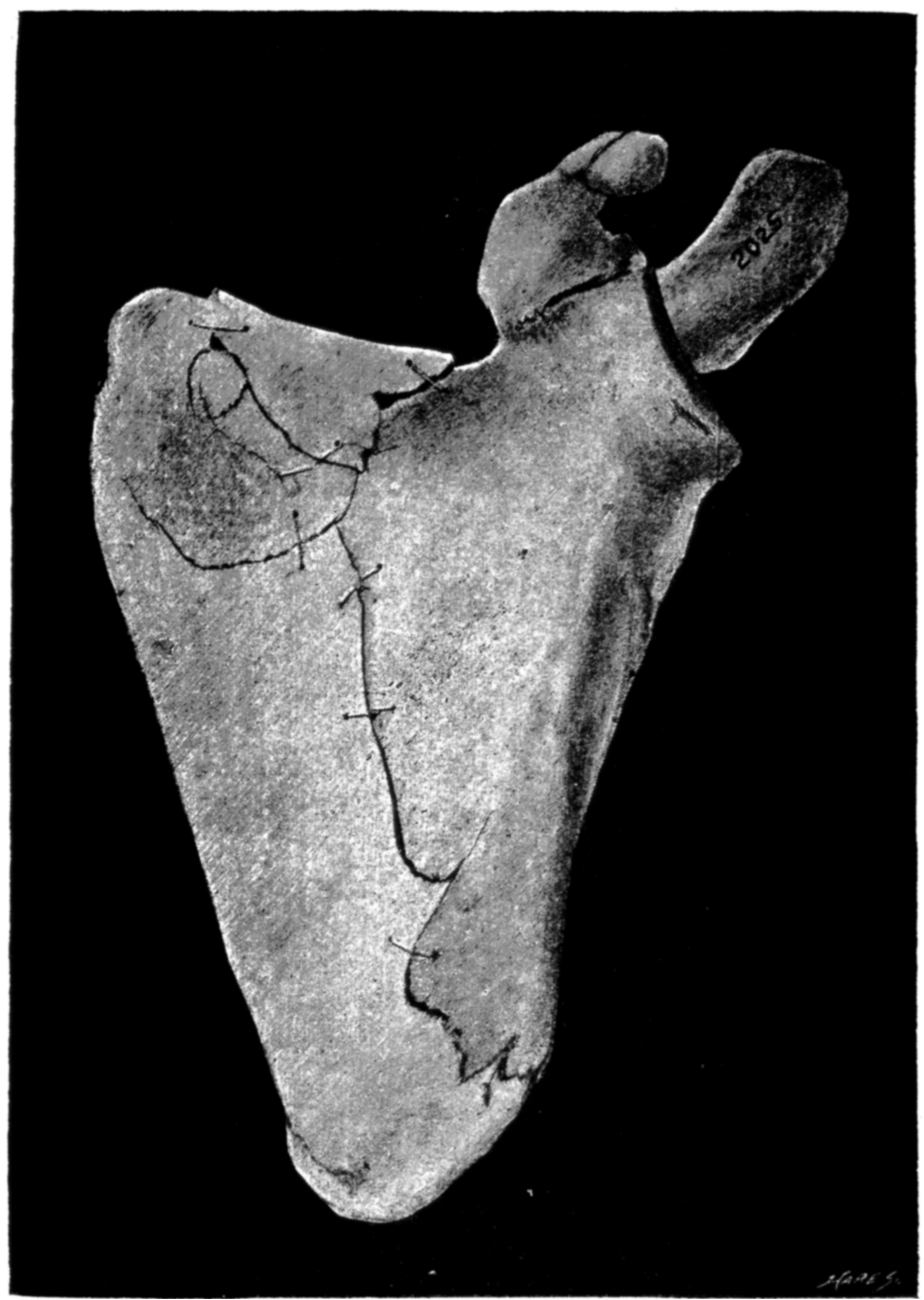

Recent Vertical Fracture of the Scapula. 
For all these assertions I have given, I think, ample proof, pathological, clinical, and experimental ("Annals of Surgery," Vol. I.), nor has any one yet shaken my faith in their truth. Are not these studies of type a help at the bedside? Could we extend the like research to other bones, might we not also gain more accuracy of diagnosis in their lesions?

Fig. 8.

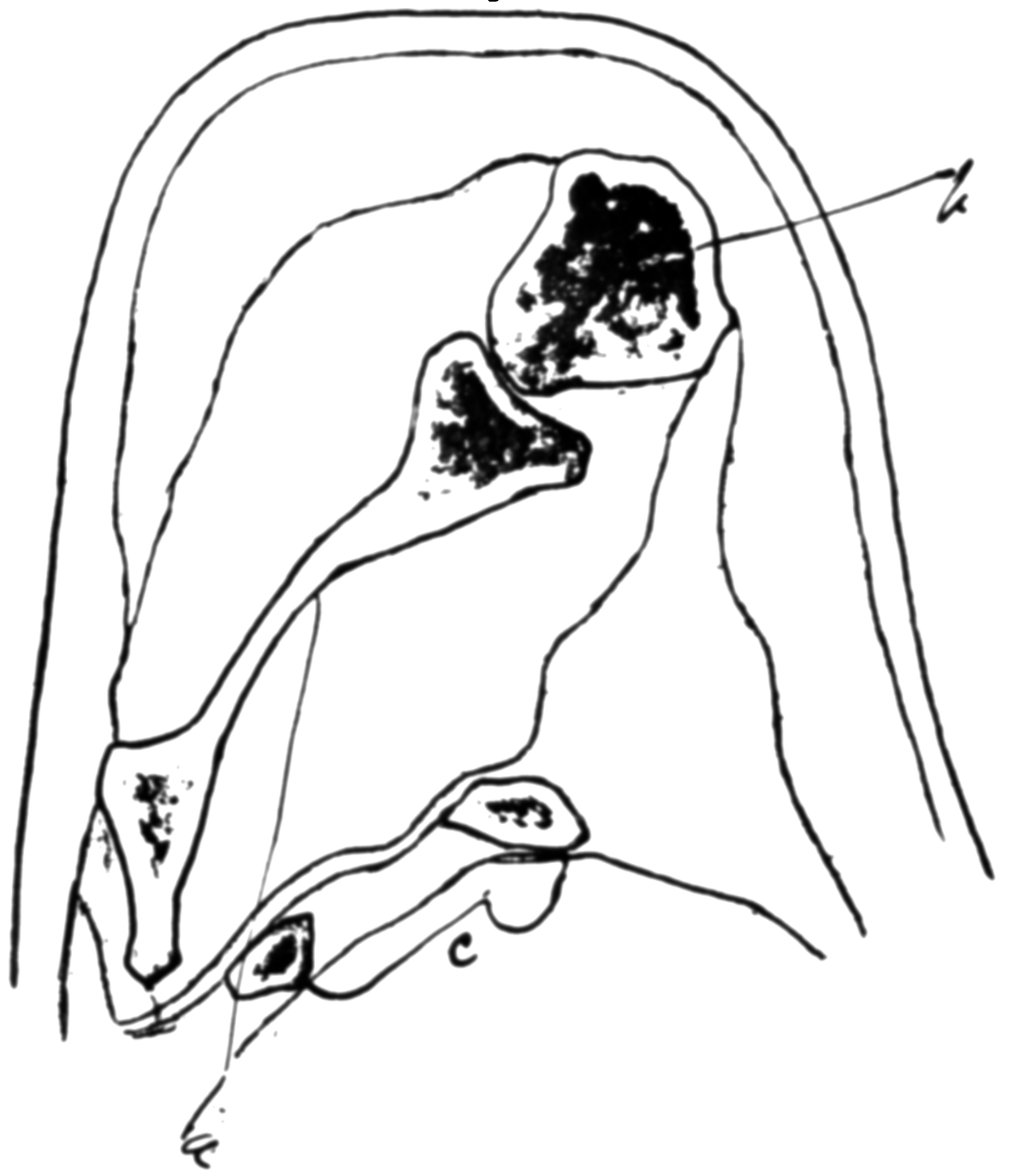

Horizontal Frozen Section of Scapular Region through the Shoulder-joint. $a$, Scapula. b, Humerus. c, Ribs. 
Let me turn for a moment to another illustration.

In regard to fractures of the scapula (Figs. 6, 7), I hold that our textbooks are astray. Without exception, they assert that fractures of the body of the scapula are produced by direct injury.

Does it not seem strange, in view of the vast variety of forces that produce these lesions, that our pathological collections should prove that two great types of fracture are observable, and that all the ordinary fractures of the body of the bone conform to these two?

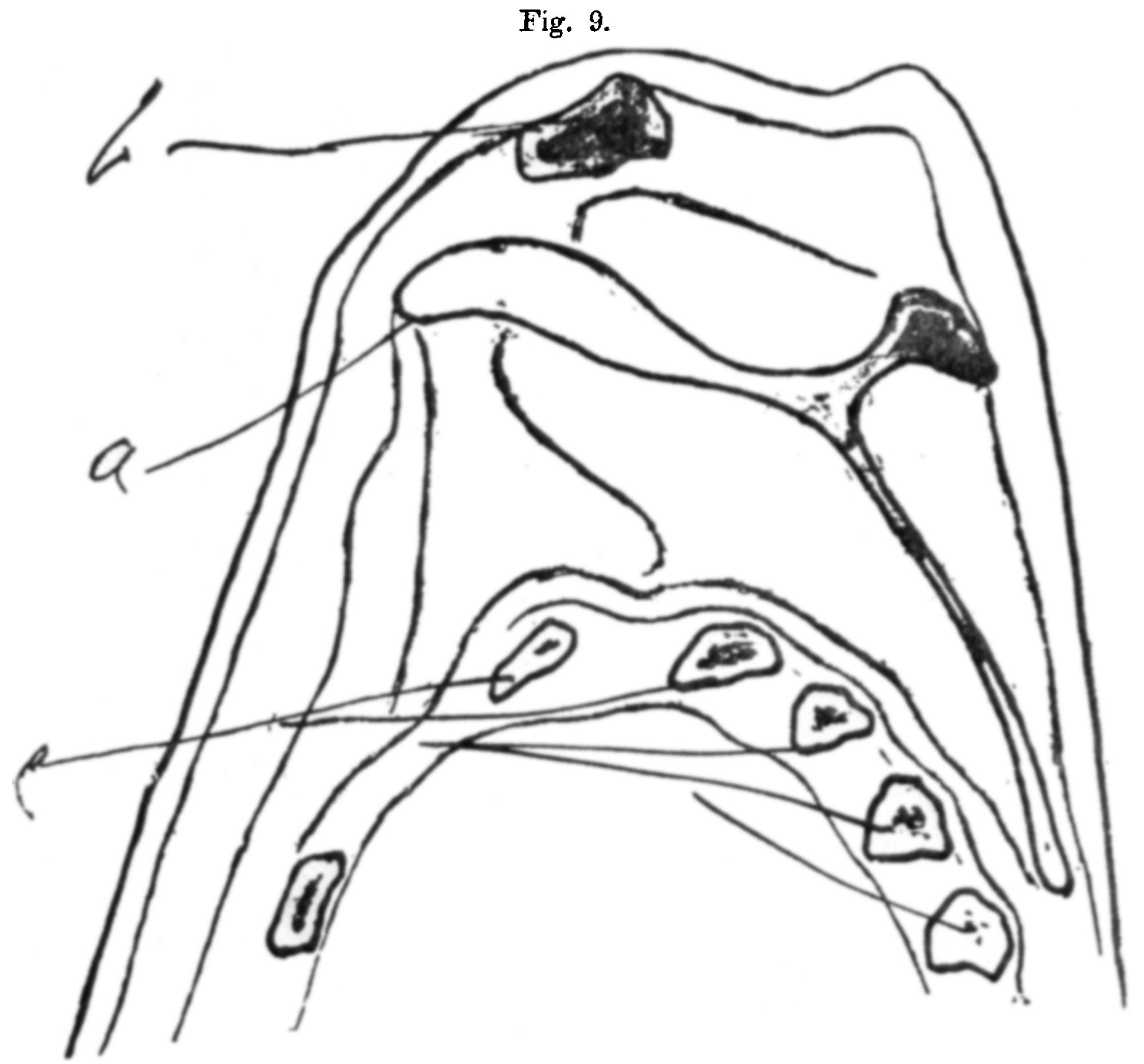

Frozen Section vertically carried through the Shoulder $a$, Scapula. b, Clavicle. $c$, liibs.

What is it that reduces, so to speak, forces acting in very varied directions to such limited results? I say the curves of the 
Fig. 10 .

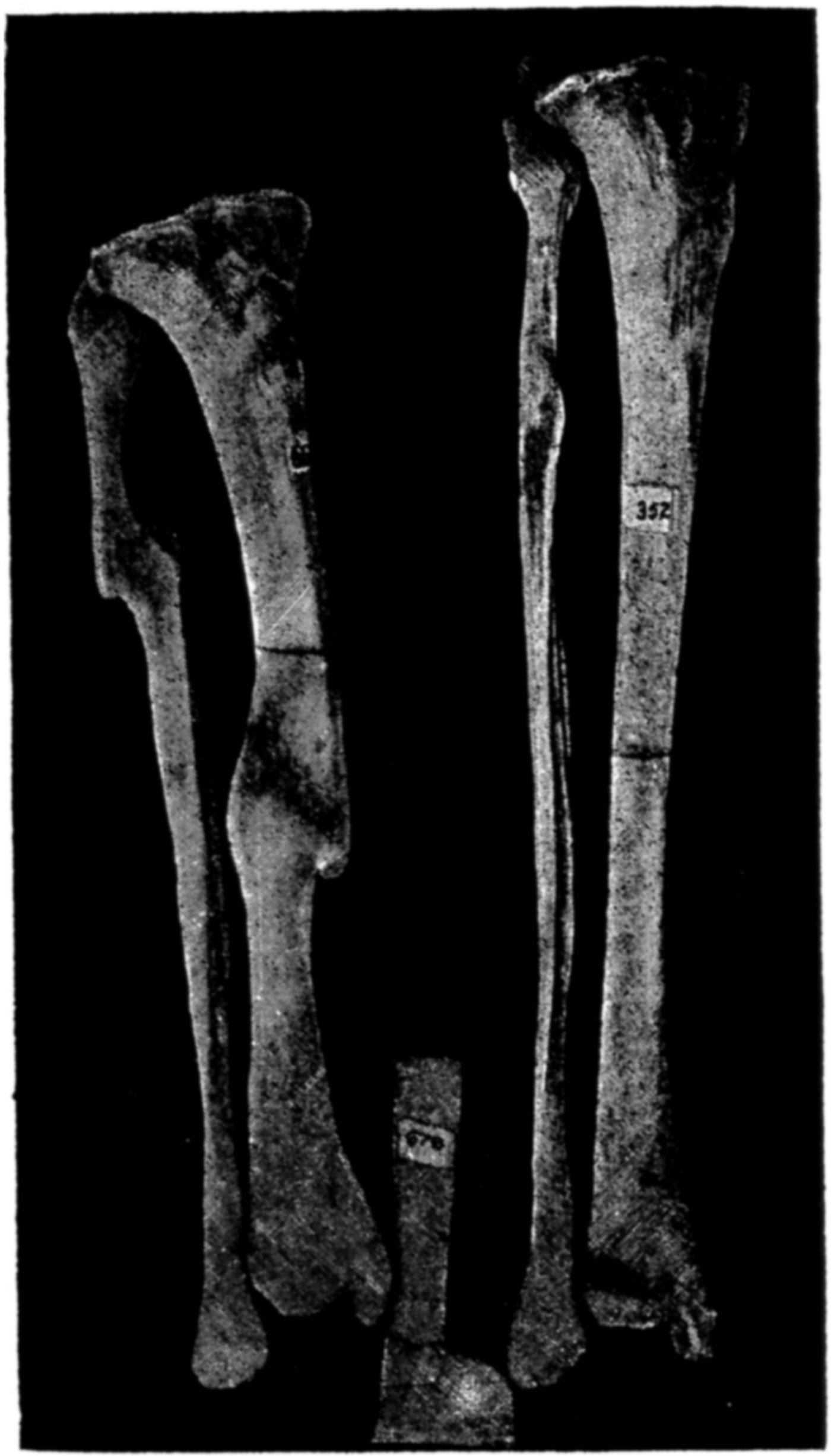

Fig. 11 . 
scapula. When a man is crushed beneath the mass of a falling pile of timber or of masonry, or a wheel passes over his shoulder as he lies prone on the ground, his scapula, supported on its edges by the trunk and outside by the shoulder, bears the pressure, and yields transversely (Fig. 6) or longitudinally (Fig. 7), according as either arch feels the strain. These, then, are all fractures from indirect force, and they are reduced to type by the constant form and shape of the bone. One clinical fact attests this. Did anyone who has treated these fractures ever see them compound, as they must frequently be if they always result, as our books say, from direct injury?

Turn to the leg for another illustration. A direct blow on the shin will break the bones of the leg transversely; an indirect strain by fall on the feet or otherwise breaks the bones obliquely; the oblique fracture will obviously be the more common. I heard once a great teacher say, perhaps with a savour of hyperbole in his assertion, to accentuate this relative frequency, " $O f$ one hundred fractures of the leg, ninety-nine will be oblique from above and behind, downwards and forwards." This overstates the case, but it expresses the typical character of these fractures familiar to every surgeon (Fig. 10). I saw the other day an evident transverse fracture of both bones of the leg. Asking the cause, the patient asserted that he had slipped on the kerb-stone and fell. He was ready with every detail of his fall. His statement was much at variance with my views, which $I$ have put before you. I discussed them with my class. Next day the solution of the difficulty appeared; the leg was broken by a kick inflicted by a policeman, from whom our patient sought to rescue a prisoner. Fearing arrest and detention in Mountjoy Prison instead of Sir P. Dun's Hospital, the ready lie, attested by many oaths, was offered to shake my faith in typical fractures.

In this situation, again, we see how great importance attaches to the exhaustive study of type. M. Gosselin has shown that when the oblique fracture varies its plane so that the letter $\mathbf{V}$ becomes fairly developed on the subcutaneous surface of the tibia, although the fracture is seated far from the ankle, and no overt 
sign discloses a fracturing of the lower fragment, there passes a fissure to the ankle along the back of the tibia, opening up its cavity while it lacerates the medullary cavity of the lower fragment throughout its entire extent. Hence the high risk to life which attends this injury, and also to the ankle-joint. When I read M. Gosselin's paper, a good many years ago, I started off to test the question in our own museum, in the collection of this college, and in the Richmond Museum.

The examples were not many-some four (Figs. 12, 13), I think ; but wherever the apex of the $V$ lay fair in the centre of the subcutaneous surface of the bone a fissure also passed spirally to the ankle, and of the four one at least had been submitted to amputation.

M. Gosselin has not touched the question of the cause of this special lesion. I have seen it in the living as the result of a twist of the limb caused by the patient turning suddenly while his foot remained fixed against the side of a ladder. A similar cause is

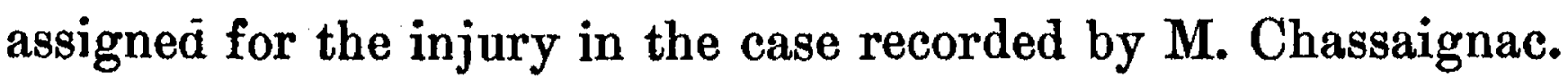

Again, exceptional characters in a fracture may catch our attention and lead to the extension of our knowledge. Everyone will admit that oblique fractures of long bones, as a rule, unite with marked deformity; in none more so than in the ordinary fracture of the leg.

Years ago I came across some very marked exceptions to this rule in the fibula, and not understanding them, $I$ put them by for further examination. As time passed I got enough to satisfy me that a family likeness pervaded all. I then saw that to answer the question I had set myself I must get the two bones of the leg in such cases. A little patience and a few years gave me enough evidence to establish the fact that in certain strains of the ankle the fibula breaks habitually in its upper part, and being held secure, unites free of deformity. I have verified the injury and its mode of occurrence, and now examples accumulate, and each recurring year submits one or mole examples of this lesion to our hospital class. Already sixteen pathological specimens expose in our museum this clearly typical fracture (Fig. 11). 
Fig. 12 .

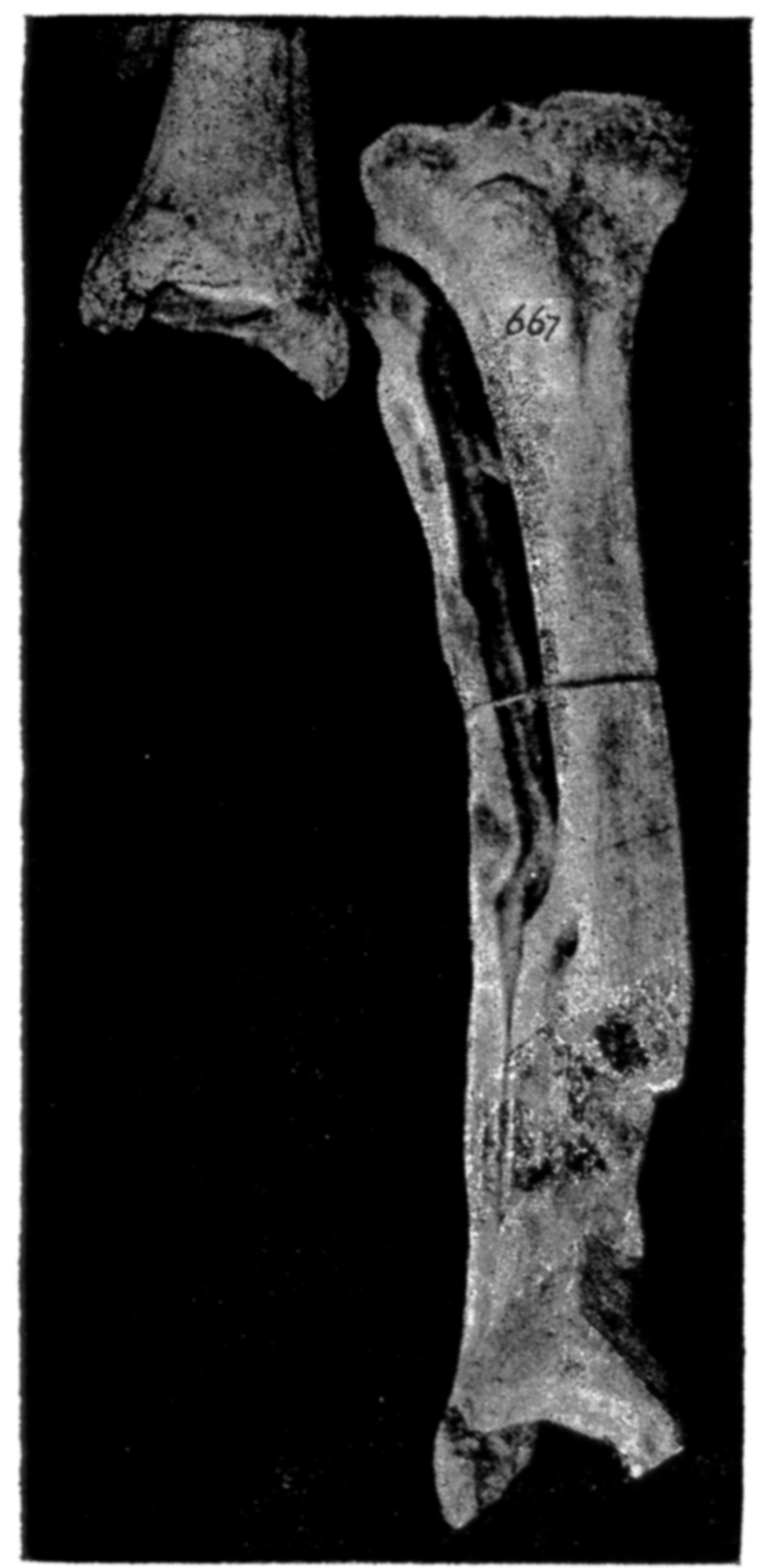


Fig. 13.

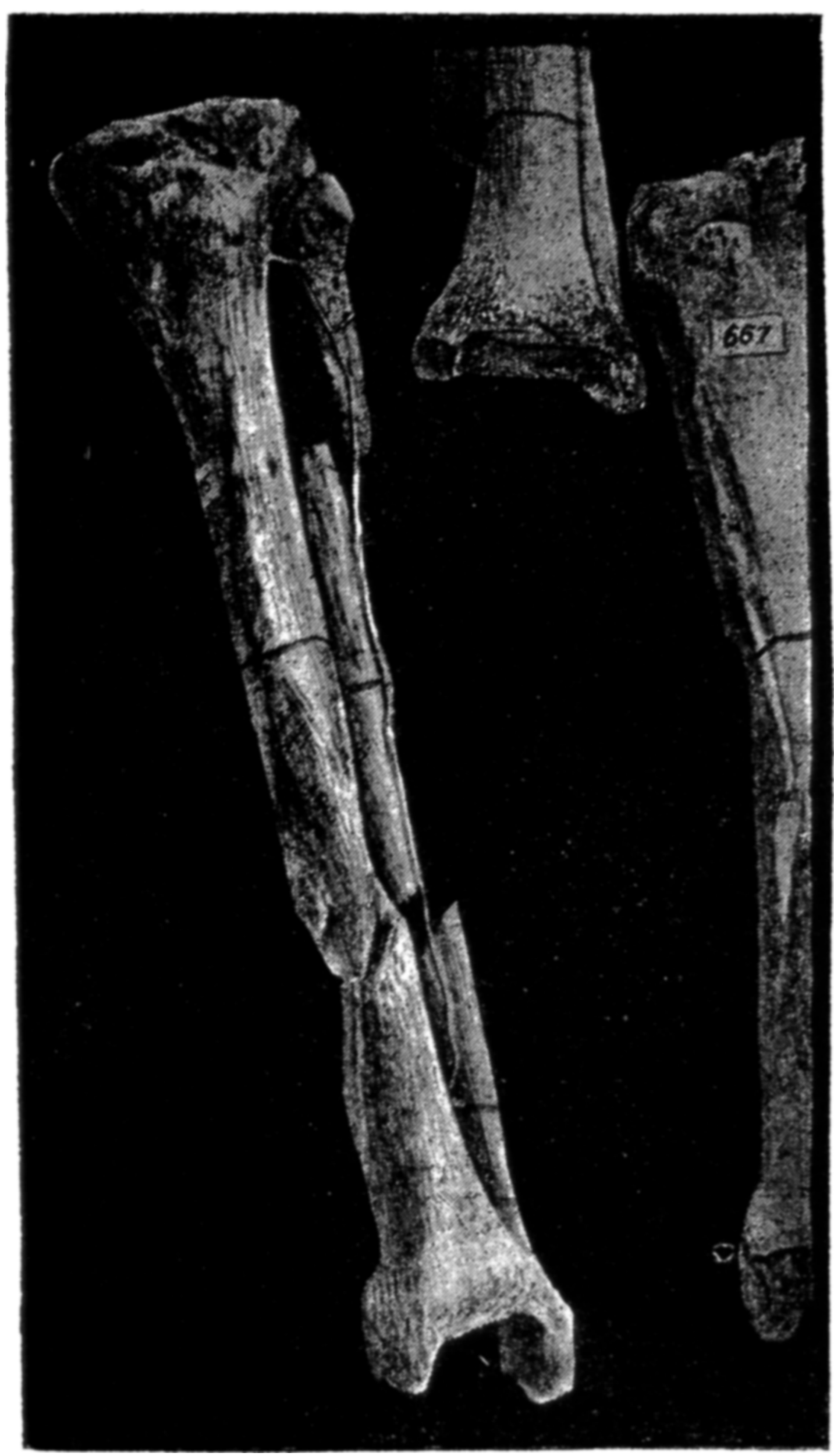


Fig. 14 .

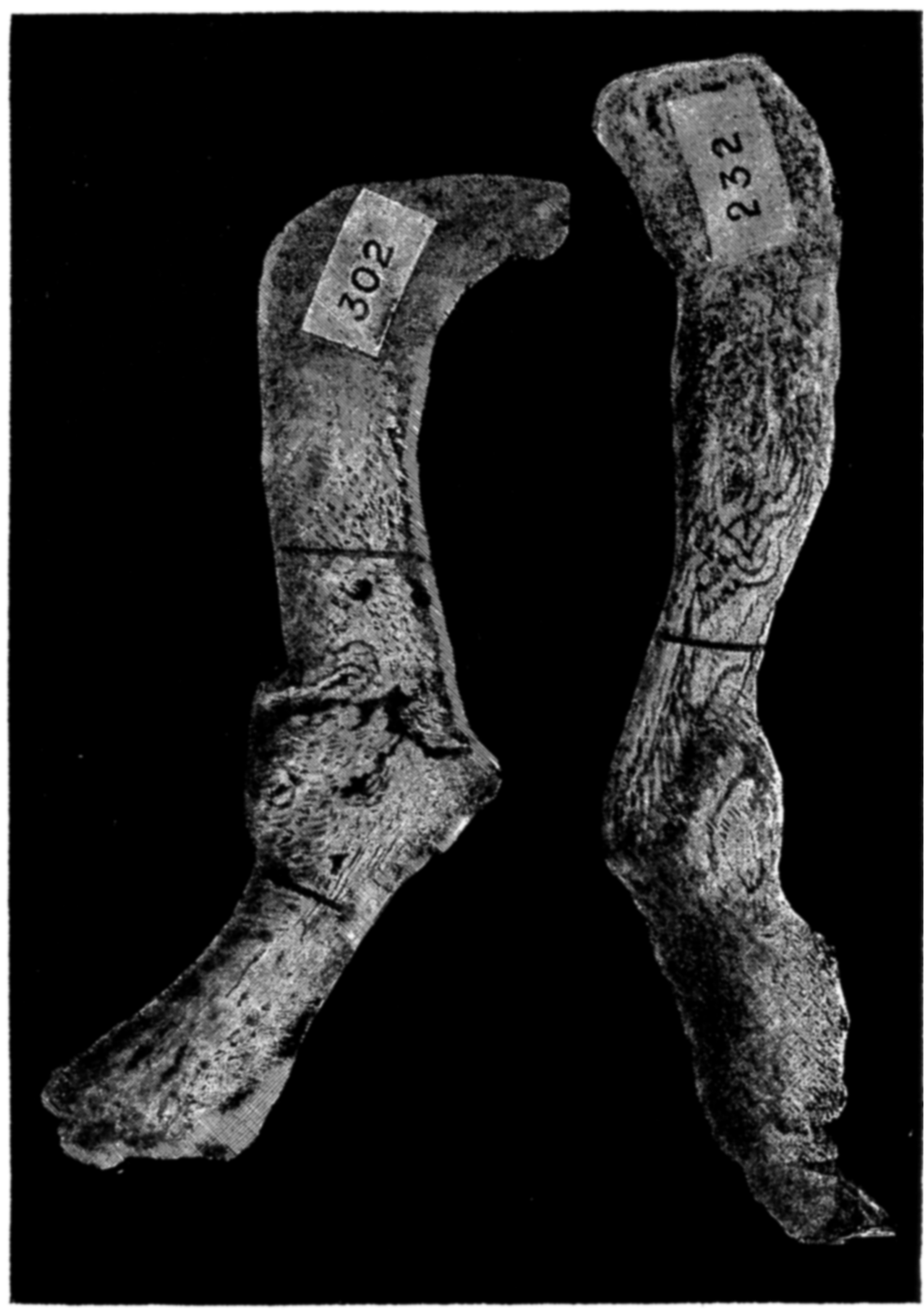

Syphilitic Clavicles, yielding exceptional Fractures. 
I fear I have tired my audience with this dry subject and these weary words, but I hope that I have at least shown that the study of the subject of fractures, based on a strict examination of the form and strength of each bone, the character of the fracturing force, with its direction, and lastly, the form of the fracture, may help us in clinical diagnosis, in prognosis, in treatment, and in medico-legal investigation.

I have touched but little on the variations of the first of my data. I could, did time permit, show that fractures of bones vary their type under the influence of structural changes induced by rickets, by syphilis (Fig. 14), and by atrophy, and the growing bone in health has its own special forms of fracture.

But enough; the geometrician can, from sufficient independent data essential to the triangle, construct the figure. I have attempted to show that, given any two of the limbs of my tripod, the surgeon may in face of the vast majority of the fractures of the skeleton deduce the third, and bring this knowledge to his aid under very varied emergencies of study or of practice. 